\title{
Mycoplasma pneumoniae Epidemiology in England and Wales: A National Perspective
}

\author{
Rebecca J. Brown ${ }^{1,2}$, Patrick Nguipdop-Djomo ${ }^{3}$, Hongxin Zhao ${ }^{1}$, Elaine Stanford ${ }^{1}$, \\ O. Brad Spiller ${ }^{2}$ and Victoria J. Chalker ${ }^{1 *}$
}

${ }^{1}$ Public Health England, London, UK, ${ }^{2}$ Department of Child Health, University Hospital Wales, Cardiff University School of Medicine, Cardiff, UK, ${ }^{3}$ Faculty of Epidemiology and Population Health, London School of Hygiene and Tropical Medicine, London, UK

\section{OPEN ACCESS}

Edited by:

Ran Nir-Paz,

Hadassah Medical Center - Hebrew

University of Jerusalem, Israel

Reviewed by:

Jonas Winchell,

Centers for Disease Control and Prevention (CDC), USA

Enno Jacobs,

Technische Universität Dresden

Germany

*Correspondence:

Victoria J. Chalker vicki.chalker@phe.gov.uk

Specialty section This article was submitted to Infectious Diseases, a section of the journal

Frontiers in Microbiology

Received: 04 December 2015

Accepted: 29 January 2016

Published: 16 February 2016

Citation:

Brown RJ, Nguipdop-Djomo P, Zhao H, Stanford E, Spiller OB and

Chalker VJ (2016) Mycoplasma pneumoniae Epidemiology in England and Wales: A National Perspective.

Front. Microbiol. 7:157.

doi: 10.3389/fmicb.2016.00157
Investigations of patients with suspected Mycoplasma pneumoniae infection have been undertaken in England since the early 1970s. M. pneumoniae is a respiratory pathogen that is a common cause of pneumonia and may cause serious sequelae such as encephalitis and has been documented in children with persistent cough. The pathogen is found in all age groups, with higher prevalence in children aged 5-14 years. In England, recurrent epidemic periods have occurred at $\sim 4$-yearly intervals. In addition, low-level sporadic infection occurs with seasonal peaks from December to February. Voluntarily reports from regional laboratories and hospitals in England from 1975 to 2015 were collated by Public Health England for epidemiological analysis. Further data pertaining cases of note and specimens submitted to Public Health England from 2005 to 2015 for confirmation, molecular typing is included.

Keywords: Mycoplasma pneumoniae, epidemiology, England, wales, microbiology

\section{INTRODUCTION}

Mycoplasma pneumoniae is a respiratory bacterial pathogen causing upper and lower respiratory disease in humans of all ages. It is a major cause of community-acquired pneumonia (CAP) and is considered to be responsible for $15-20 \%$ of CAP cases in adults and up to $40 \%$ of cases in children, especially in children of school age (Foy, 1993; Korppi et al., 2004; Dumke et al., 2012). Up to 25\% of $M$. pneumoniae infections may manifest as extra-pulmonary sequelae after the onset of or in some cases in the absence of respiratory illness (Cassell and Cole, 1981; Narita, 2010). Encephalitis is one of the most severe complications (Narita, 2009; Meyer Sauteur et al., 2014b) estimated in $5-10 \%$ of pediatric encephalitis patients (Bitnun et al., 2001; Christie et al., 2007) of which up to $60 \%$ of have additional neurologic sequelae (Bitnun et al., 2001, 2003). M. pneumoniae infection can result in dermatological manifestations including Stevens-Johnson syndrome (Olson et al., 2015). Hemolytic anemia is a rare but serious complication of $M$. pneumoniae infection and is more frequent children than in adults (Gu et al., 2014). M. pneumoniae infections occur both endemically and epidemically worldwide, with epidemic peaks every 4-7 years (Chalker et al., 2011a, 2012a; Jacobs, 2012). Typical outbreaks of M. pneumoniae infection occur in areas of close personal contact for example, schools and military barracks. Both symptomatic and asymptomatic individuals with M. pneumoniae carry the organism in the respiratory tract and it can be transmitted from person to person via aerosols and cough (Clyde, 1979; Waites and Talkington, 2004; Meyer Sauteur et al., 2014c). Long-term morbidity due to M. pneumoniae infection is uncommon however; the acute illness is often disruptive and can consume significant resources (Waites and Talkington, 2004). 
In England and Wales (EW), seasonal peaks of infection are detected from December to February each year with epidemics at $\sim 4$-yearly intervals (Chalker et al., 2011b, 2015). Cyclical patterns, as observed in EW, are also seen in Denmark, Sweden, Norway, Finland, Korea, and Japan (Ito et al., 2001; Rasmussen et al., 2010; Blystad et al., 2012; Linde et al., 2012; Polkowska et al., 2012; Kim et al., 2015). It has recently been suggested that minor variations in the duration of immunity may be essential to the cyclic epidemic peaks (Omori et al., 2015). A con-current increase in reported M. pneumoniae cases was documented in several European countries in 2011 (Lenglet et al., 2012) and in EW the most recent increase has been noted in 2015 (this study).

The recent global increase in macrolide resistance observed in cases of $M$. pneumoniae infection is of increasing concern and importance to the international community (Bébéar, 2012). In China resistance has been documents in over $90 \%$ of clinical isolates of M. pneumoniae studied (Zhao et al., 2013) however resistance is lower in European counties including France, Germany, Switzerland, and Sweden (Peuchant et al., 2009; Meyer Sauteur et al., 2014a; Nilsson et al., 2014; Dumke et al., 2015). Macrolides are currently recommended as the first-line treatment for M. pneumoniae infection in the UK (Harris et al., 2011). The 2011 British Thoracic Society guidelines for the management of CAP in children and adults suggest empirical macrolide treatment at any age if there is no response to firstline $\beta$-lactam antibiotics (which are ineffective against cell wallless bacteria such as $M$. pneumoniae) or in the case of very severe disease (Lim et al., 2009; Harris et al., 2011). Macrolideresistance in EW has recently been documented at $9.3 \%$ and is therefore not included in this article (Brown et al., 2015a). This is considerably lower than in Scotland (19\%) (Ferguson et al., 2013).

This study aims to provide up to date overview of the number of laboratory reports and incidence of $M$. pneumoniae infection in EW, molecular typing data, and briefly highlight cases of note in recent years.

\section{MATERIALS AND METHODS}

A total of 16,878 serological, culture, genomic, and unspecified laboratory diagnostic methodology M. pneumoniae positive cases reported to Public Health England, via the Communicable Disease Report Network comprising 250 laboratories from January 1989 to June 2015 were aggregated into 3 weekly periods. These report the organisms identified from specimens (e.g., throat swabs, serum, or sputum) submitted by general practitioners and hospitals with the patient's age and sex, the reporting laboratory, and date of the first sample; the system has changed little over time. Duplicate specimens were removed and reports plotted to examine the general pattern (3-weekly moving average). National reporting categories include antibody detection and antibody-detection rising titre. A rising titre is defined as a four-fold increase in detectable anti-M. pneumoniae antibody level. Rising titres are not demonstrated for all patients as it is not always possible to obtain a second specimen. It is possible that a fraction of cases reported as antibody detection only include some cases of rising titre that have not been appropriately coded. A distinction between $\operatorname{IgA}, \operatorname{IgG}$ and $\operatorname{IgM}$ cannot be made when collating figures, however the number of cases with rising titre demonstrating active infection mirror the overall total case pattern of epidemic periodicity. A total of 39,758 laboratory reports of M. pneumoniae infections in England and Wales from January 1975 to June 2009 previously examined indicated that cyclic epidemics occurred every 4 years, were synchronous across all regions in the country, and occurred during the winter (Nguipdop-Djomo et al., 2013). Epidemic periods were defined as a clear increase in cases resulting in more than 20 cases in a 3 weekly average rolling period (Figure 1). From this dataset, we computed average age specific incidence for epidemic and non-epidemic periods using the England and Wales (EW) population censuses of 1981, and 2001 for the denominator for the periods 19751988 and 1998-2009 respectively. Data from 1989 to 1997 were excluded from age-specific analyses because age was missing in $\sim 90 \%$ records during that period. Age distribution incidence rates from 2010 to June 2015 were calculated using the Office for National Statistics (ONS) mid-year population estimates for EW.

Diagnostic methodology of choice has altered with time in $\mathrm{EW}$, with the decline in culture and use of the complement fixation test being superseded by enzyme immunosorbent assays and the introduction of molecular testing. To ascertain the proportion of reports now obtained using molecular methods, differing methodologies in use with time was examined from 1989 to 2015 (Figure 2). Molecular typing of M. pneumoniae positive clinical specimens and isolates was undertaken using MLST (50) (Brown et al., 2015b), MLVA (156) (Chalker et al., 2015), and P1 type (84) determinations (Dumke et al., 2006) from 1977 to 2011 (Figures 3-5). Referred cases to the Bacteriology Reference Department, Public Health England from 2005 to 2015 were examined for cases with unusual or severe presentation.

\section{RESULTS}

From January 1989 to June 2015 seven epidemics of M. pneumoniae were noted of declining amplitude with recent peak in 2015 (Figure 1). For some epidemic periods clear annual fluctuations can also be seen apparent as a double peak over two winter seasons. The clarity of epidemic periods have in recent years declined with less reported cases overall. From 1975 to 2009 incidence was found to be similar by gender, both during epidemic and inter-epidemic periods. The annual notification rate in 2010-2015 was consistently highest in those aged 15-44 years, detailed in Table 1. The use of culture has declined in recent years and despite serology being the most commonly used methodology the implementation and increased use of molecular methods has resulted in a proportional increase in reports based on molecular tests from $0.32 \%(3 / 93695 \%$ CI $0.06-0.98)$ in 2010 to $28.5 \%$ (95/333 95\%CI 24.0-33.6) in the first 6 months of 2015 (Figure 2). Molecular typing data were grouped into 4-yearly 


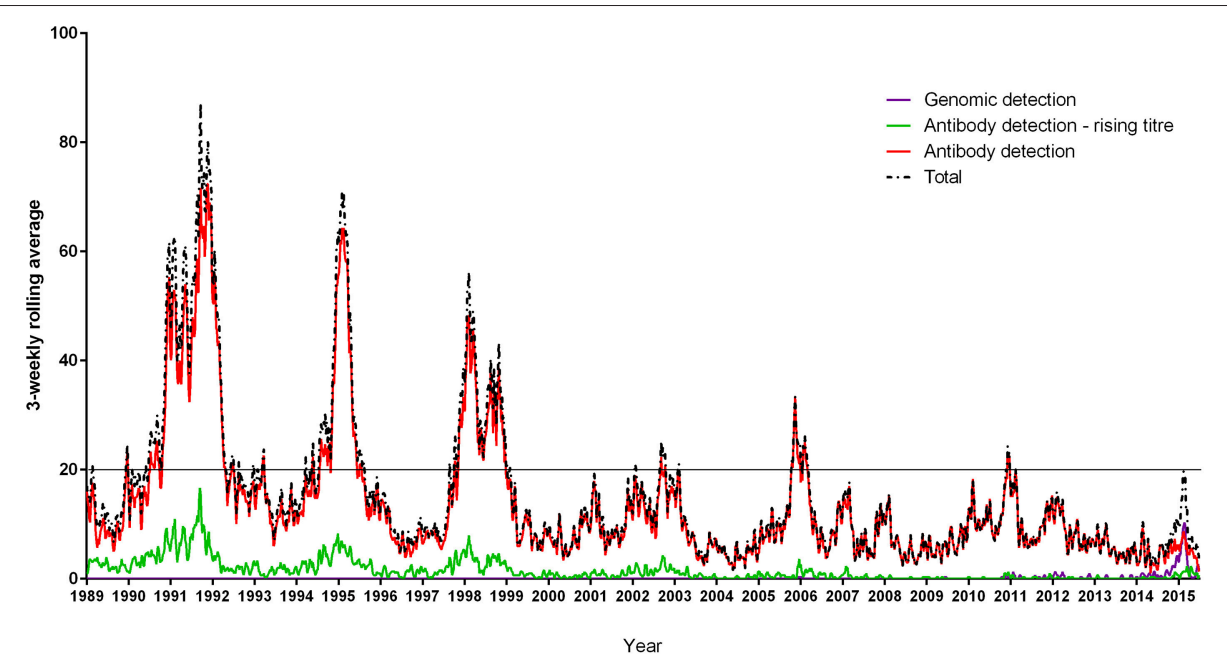

FIGURE 1 | Laboratory reports of Mycoplasma pneumoniae infection detection by genomic and serological methods in England and Wales from January 1989 to June $\mathbf{2 0 1 5}$. The line at 20 cases per 3 weekly average rolling period defines seven epidemic periods of declining magnitude and clarity, lasting up to 2 years (1991-1992, 1994-1995, 1998-1999, 2001-2003, 2005-2006, 2011, 2015). National reporting categories include antibody detection and antibody-detection rising titre. A rising titre is defined as a four-fold increase in detectable anti-Mycoplasma pneumoniae antibody level.

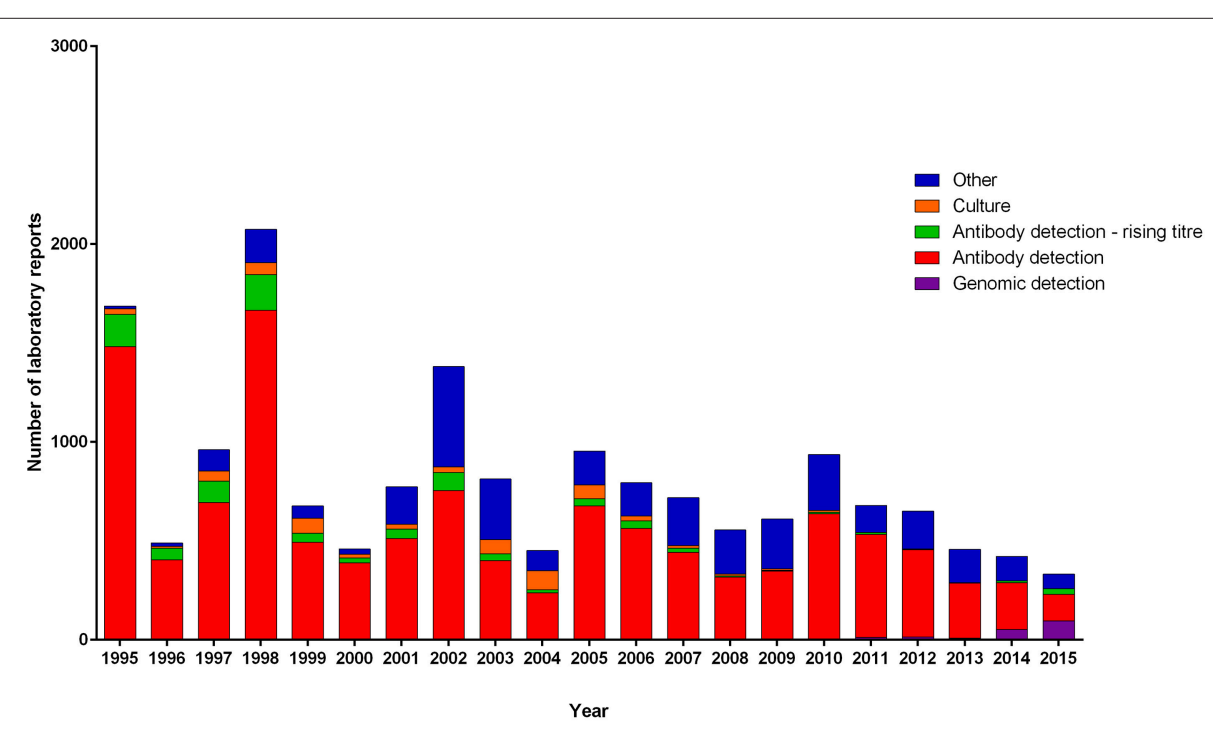

FIGURE 2 | Number of laboratory reports per year from January 1995 to June 2015 separated by detection methodology. National reporting categories included are: antibody detection and antibody-detection rising titre. A rising titre is defined as a four-fold increase in detectable anti-Mycoplasma pneumoniae antibody level (methods not specified). Other indicates specimens for which M. pneumoniae infection was determined using antigen detection (method not specified), microscopy and unknown categories. Culture indicates cases from which specimens yielded isolates of M. pneumoniae and genomic detection those for which DNA of $M$. pneumoniae was detected by PCR.

intervals, representing the epidemic cycles observed in the UK. Multiple MLST, MLVA, and P1 types were observed in each 4-yearly interval (3-5) however a predominance of P1 type 1 can be seen for all intervals except 1981-1984 where equal numbers of P1 type 1 and type 2 strains were observed. This data is limited by low sample number in 4-yearly intervals, therefore the variation in P1 types observed is likely to be an underestimate of the actual M. pneumoniae population present.

\section{Cases of Note: 2005-2015}

From January 2005 to June 2015 eleven cases were referred to the Bacterial Reference Department, Public Health England that were identified as positive for $M$. pneumoniae that were of particular note. The majority of cases were patients with lower respiratory tract infection. Stevens-Johnson syndrome is an immune-mediated hypersensitivity complex typically involving the skin and mucous membranes. Two cases of Stevens-Johnsons 


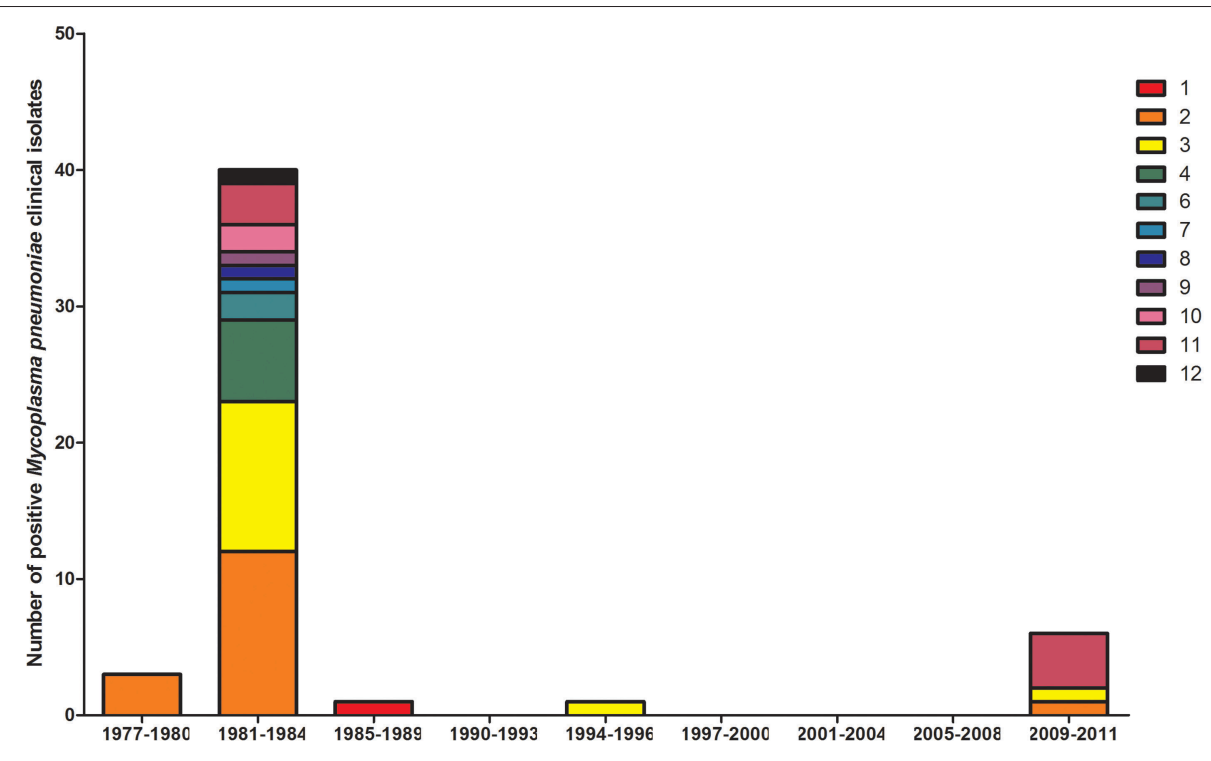

FIGURE 3 | Distribution of MLST sequence types for 57 M. pneumoniae clinical isolates in the 4-yearly epidemic cycles observed in the UK. Year groups indicative of epidemic periods are listed on the $x$-axis. Sequence types (ST) 1-12 are listed in the key and indicated with differing colors. Allelic profiles are available on http://pubmlst.org/mpneumoniae.

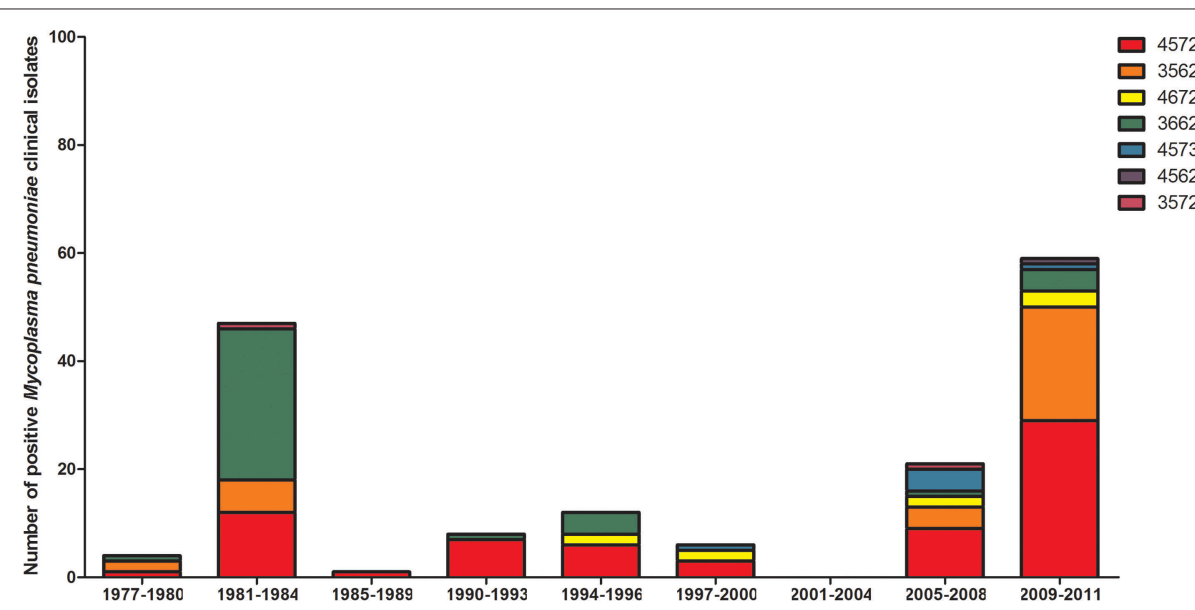

FIGURE 4 | Distribution of MLVA types in positive M. pneumoniae clinical specimens/isolates collated into the 4-yearly epidemic cycles observed in the UK. Year groups indicative of epidemic periods are listed on the $x$-axis. MLVA profiles are listed in the key and indicated with differing colors.

syndrome were noted in 2009 and 2010 in male children aged 8 and 6 respectively. Two cases were noted in respiratory specimens in immunocompromised patients following extrapulmonary organ transplantation (2013 and 2015). Infection in donor transplant patient respiratory secretions was also noted in 2015. M. pneumoniae was detected by qPCR in the nasopharyngeal aspirate but not the cerebral spinal fluid (CSF) of a patient with pneumonia and reactive transverse myelitis in a child in 2005, and in the bronchoalveolar lavage of a child with encephalitis and seizures in 2011. In 2011 a young adult patient presented post respiratory tract infection with encephalitis and transverse myelitis that progressed to tetraplegia with ventilator dependency. M. pneumoniae was confirmed by qPCR on throat swab specimens taken 19 and 21 days post onset but was not detected in concurrent CSF specimens (Chalker et al., 2012b). Detection of M. pneumoniae in CSF is unusual and it is postulated that neurological manifestation of M. pneumoniae infection is antibody mediated rather than by direct presence of the bacteria itself (Waites and Talkington, 2004). Of 68 CSF specimens referred only 1 positive case was detected in 2010, in a child with a ventriculoperitoneal shunt, in which contamination of the CSF during sampling could not be excluded. In 2012 M. pneumoniae was detected by qPCR in the lung tissue of two co-habiting adults that both suffered sudden fatal collapse. This was presumed a secondary infection as one of the two patients also had confirmed Staphylococcus aureus infection. 


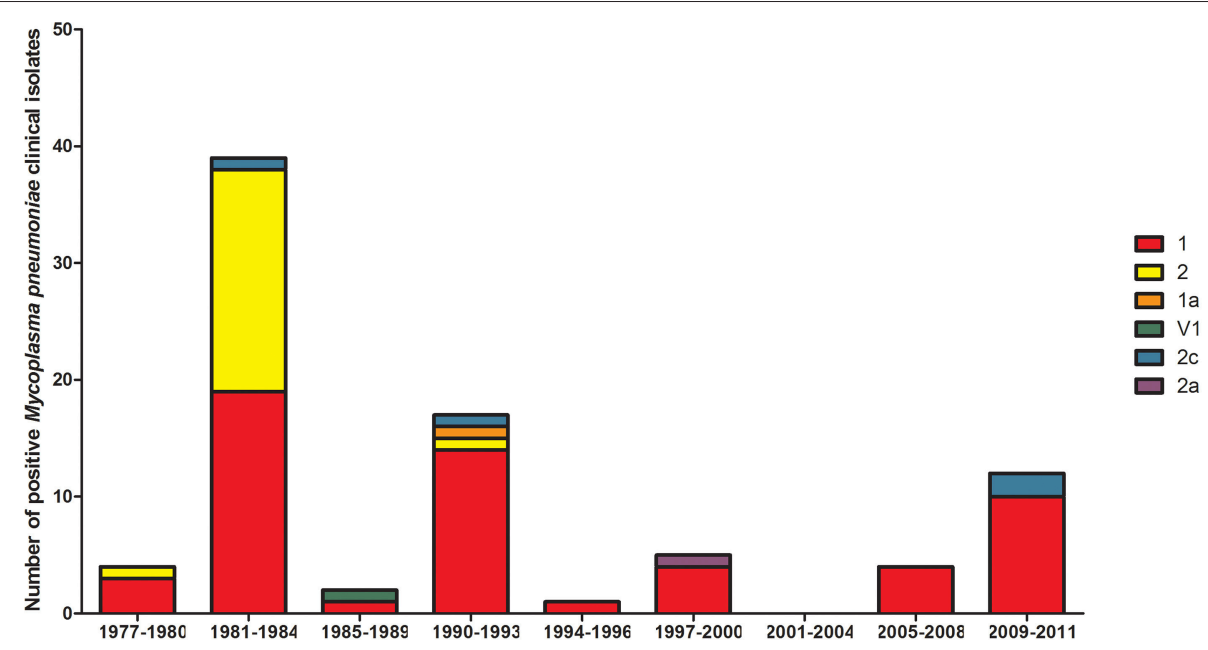

FIGURE 5 | Distribution of P1 type in 4-yearly epidemic cycles observed in the UK for positive M. pneumoniae clinical specimens/isolates. Year groups indicative of epidemic periods are listed on the $x$-axis. P1 types are listed in the key and indicated with differing colors.

TABLE 1 | Incidence of $M$. pneumoniae positive laboratory reports per million persons.

\begin{tabular}{|c|c|c|c|c|c|c|c|c|c|c|}
\hline & \multirow[t]{2}{*}{ Year } & \multicolumn{9}{|c|}{ Incidence (per million persons in overall population) } \\
\hline & & $0-4$ years & $5-9$ years & $10-14$ years & 15-24 years & $25-44$ years & $45-64$ years & $65+$ years & Unknown & Total \\
\hline \multirow[t]{7}{*}{ Serology + PCR } & 2010 & 1.17 & 1.35 & 0.99 & 1.40 & 2.09 & 1.44 & 0.61 & 0.00 & 9.05 \\
\hline & 2011 & 1.14 & 1.83 & 1.16 & 1.51 & 2.40 & 1.28 & 0.87 & 0.02 & 10.21 \\
\hline & 2012 & 1.45 & 1.47 & 1.15 & 1.45 & 2.84 & 2.05 & 1.22 & 0.00 & 11.63 \\
\hline & 2013 & 0.61 & 0.95 & 0.74 & 0.93 & 1.77 & 1.82 & 1.42 & 0.00 & 8.25 \\
\hline & 2014 & 0.82 & 0.78 & 0.47 & 0.89 & 2.09 & 1.10 & 1.31 & 0.02 & 7.47 \\
\hline & $2015^{\star}$ & 1.78 & 1.22 & 0.70 & 1.15 & 3.07 & 1.88 & 1.32 & 0.00 & 11.11 \\
\hline & Average & 1.16 & 1.27 & 0.87 & 1.22 & 2.38 & 1.60 & 1.13 & 0.01 & 9.62 \\
\hline
\end{tabular}

*Data for 2015 from January to June and rates adjusted for half-year data were collected.

\section{DISCUSSION}

Laboratory reports show that cyclic epidemics of $M$. pneumoniae infections in EW recur every 4 years on average, concurrent with annual seasonal fluctuations with incidence peaking and dipping in the winter and summer respectively. The reduction in clarity and magnitude of epidemic periods in recent years could be indicative of a genuine reduction in cases, increasing population pulmonary health, or reflect the changing nature of testing strategies moving away from techniques such as complement fixation. Overall incidence, although declining over the period 1989-2015, has remained static since 2010 and agespecific differences in epidemic period incidence were noted for the limited periods studied. Annual notification rate in 20102015 was highest in 15-44 year olds perhaps reflecting reliance on serological confirmation or infection. Globally, epidemics of M. pneumoniae are considered to occur every 3-7 years, however recent epidemiological studies have documented varying trends in epidemic patterns. Serological studies performed in Denmark showed a pattern of $M$. pneumoniae infections over a 50 year period from 1946 through 1995 with endemic disease transmission punctuated with cyclic epidemics every 3-5 years (Lind et al., 1997). In Jerusalem, historically, epidemics were observed every 3-5 years with seasonal peaks in October and early spring; however, since autumn 2014 a constant rate of infection has been observed, diverging from the historical pattern (Nir-Paz et al., 2012). Indeed, similar to the data for EW; 3yearly cyclic epidemic periods with declining magnitude have been documented in Japan from 1979 to 1999 (Ito et al., 2001).

Speculations regarding the mechanisms driving fluctuations in population incidence of $M$. pneumoniae infections have included decline in immunity or increase of the immunologically naive population level (Chalker et al., 2011a) or shifts in the proportion of individual strains with specific P1 type or concurrent increased incidence of several strains. Additionally, it is believed that the genotype of $M$. pneumoniae may be changing, generating diverse genetic material in each epidemic with a study reporting the detection of polyclonal strains in a single epidemic (Pereyre et al., 2012). Recent modeling of epidemic 
peaks has suggested that fluctuations may be attributable to minor variations in the duration of immunity at the population level (Omori et al., 2015). Speculation that a shift in P1 adhesin type may be the cause of epidemics has been disputed with evidence indicating the presence of multiple P1 adhesin types in observed increases of infection (Sasaki et al., 1996; Dégrange et al., 2009; Pereyre et al., 2012). It was hypothesized that a decline in immunity or an increase of the immunologically naïve population may result in the 4-year cycle of epidemic periods (Chalker et al., 2011a). In other geographical locations, it has also been observed that multiple P1 types can be detected during outbreaks, and it has been suggested that although immunological pressure may favor shifts of P1 type, a cocirculation of P1 types appears to be common (Nilsson et al., 2010; Dumke et al., 2015). This is further supported by the presence of multiple MLST types within specimens in EW, reflecting the concurrent presence of strains of varied genetic lineage. As expected an increase in molecular detection of infection is noted, with declining use of culture. Macrolide resistance has recently been documented at 9.3\% found in adult patients only (Brown et al., 2015a) and is also of concern in children in other countries (Meyer Sauteur et al., 2014a). However, this was derived from results of specimens submitted to the reference laboratory which may be biased toward those developing resistance during treatment and one patient was documented to have received macrolides prior to sampling therefore this level may be an over-representation to the actual level in the community.

Extrapulmonary complications of $M$. pneumoniae infection can arise involving the skin and the nervous, cardiovascular, renal, gastrointestinal, musculoskeletal, and hematologic systems. The presence of $M$. pneumoniae in these extrapulmonary sites has been confirmed by PCR as well as culture (Koletsky and Weinstein, 1980; Kasahara et al., 1985; Narita et al., 1996; Saïd et al., 1999; Bar Meir et al., 2000). Complications that occur within the central nervous system (CNS) are recognized as the most common extrapulmonary manifestations of $M$. pneumoniae infections. A recent study of 1988 children with encephalitis showed M. pneumoniae as the most common causative agent (Bebear and Robertson, 1996). It is thought that the host immune response that

\section{REFERENCES}

Bar Meir, E., Amital, H., Levy, Y., Kneller, A., Bar-Dayan, Y., and Shoenfeld, Y. (2000). Mycoplasma pneumoniae-induced thrombotic thrombocytopenic purpura. Acta Haematol. 103, 112-115. doi: 10.1159/0000 41030

Bébéar, C. (2012). Editorial commentary: infections due to macrolide-resistant Mycoplasma pneumoniae: now what? Clin. Infect. Dis. 55, 1650-1651. doi: $10.1093 / \mathrm{cid} / \mathrm{cis} 791$

Bebear, C., and Robertson, J. A. (1996). "Determination of minimal inhibitory concentration," in Molecular and Diagnostic Procedures in Mycoplasmology, eds J. G. Tully and S. Razin (New York, NY: Academic Press), 189-197.

Bitnun, A., Ford-Jones, E., Blaser, S., and Richardson, S. (2003). Mycoplasma pneumoniae ecephalitis. Semin. Pediatr. Infect. Dis. 14, 96-107. doi: $10.1053 /$ spid.2003.127226 develops after M.pneumoniae infection contributes to these complications as well as contributing to autoimmunity (Waites and Talkington, 2004). The mechanisms that result in these neurological manifestations of $M$. pneumoniae infection are not completely understood however, immune-mediated mechanism are suspected due to the development of cross-reactive antibodies to the brain and other neurological structures (Waites et al., 2008). PCR testing of 68 CSF specimens in EW resulted in detection of $M$. pneumoniae DNA in a single specimen in which contamination during sampling could not be excluded. Consideration to testing of CSF specimens in tandem with paired respiratory specimens should be given as in practice detection of $M$. pneumoniae in CSF is extremely rare and positive patients may be detected using pulmonary specimens.

In summary, epidemics of $M$ pneumoniae infections recur every 4 years on average in EW affecting all age groups, predominantly children and adults $<44$ years of age. Macrolide resistance has recently been documented at $9.3 \%$ and extrapulmonary complications can be severe.

\section{AUTHOR CONTRIBUTIONS}

$\mathrm{RB}$ worte the manuscript, $\mathrm{PN}, \mathrm{HZ}$, and ES undertook epidemiological data, OS and VC oversaw the study and wrote the manuscript.

\section{FUNDING}

RB studentship was funded by Cardiff University and Public Health England, all other works was funded by Public Health England.

\section{ACKNOWLEDGMENTS}

The authors are grateful to P E M Fine and E Vynnycky Faculty of Epidemiology and Population Health, London School of Hygiene and Tropical Medicine and G Dabrera and K Halsby Public Health England for epidemiological expertise and T Harrison for critical reading of the manuscript, $\mathrm{S}$ Chalker for assistance with IT, previous members of the Mollicute reference laboratory and all colleagues and patients for referring specimens.
Bitnun, A., Ford-Jones, E. L., Petric, M., MacGregor, D., Heurter, H., Nelson, S., et al. (2001). Acute childhood encephalitis and Mycoplasma pneumoniae. Clin. Infect. Dis. 32, 1674-1684. doi: 10.1086/320748

Blystad, H., Ånestad, G., Vestrheim, D. F., Madsen, S., and Rønning, K. (2012). Increased incidence of Mycoplasma pneumoniae infection in Norway 2011. Euro Surveill. 17:20074.

Brown, R. J., Holden, M. T., Spiller, O. B., and Chalker, V. J. (2015b). Development of a multilocus sequence typing scheme for molecular typing of Mycoplasma pneumoniae. J. Clin. Microbiol. 53, 3195-3203. doi: 10.1128/JCM.01301-15

Brown, R. J., Macfarlane-Smith, L., Phillips, S., and Chalker, V. J. (2015a). Detection of macrolide resistant Mycoplasma pneumoniae in England, September 2014 to September 2015. Euro Surveill. 20:30078. doi: 10.2807/15607917.ES.2015.20.48.30078

Cassell, G. H., and Cole, B. M. (1981). Mycoplasmas as agents of human diseases. N. Engl. J. Med. 304, 80-89. doi: 10.1056/NEJM198101083040204 
Chalker, V. J., Stocki, T., Litt, D., Bermingham, A., Watson, J., Fleming, D., et al. (2012a). Increased detection of Mycoplasma pneumoniae infection in children in England and Wales, October 2011 to January 2012. Euro Surveill. 17:20081.

Chalker, V. J., Stocki, T., Mentasti, M., Fleming, D., and Harrison, T. G. (2011a). Increased incidence of Mycoplasma pneumoniae infection in England and Wales in 2010: multilocus variable number tandem repeat analysis typing and macrolide susceptibility. Euro Surveill. 16.

Chalker, V. J., Stocki, T., Mentasti, M., Fleming, D., Sadler, C., Ellis, J., et al. (2011b). Mycoplasma pneumoniae infection in primary care investigated by real-time PCR in England and Wales. Eur. J. Clin. Microbiol. Infect. Dis. 30, 915-921. doi: 10.1007/s10096-011-1176-3

Chalker, V. J., Wood, A., Stocki, T., and Curtis, C. (2012b). Mycoplasma pneumoniae in a Patient with Severe Transverse Myelitis. Toulouse: IOM.

Chalker, V., Pereyre, S., Dumke, R., Winchell, J., Khosla, P., Sun, H., et al. (2015). International Mycoplasma pneumoniae typing study: the interpretation of Mycoplasma pneumoniae multilocus variable-number tandem-repeat analysis. New Microbes New Infect. 7, 37-40. doi: 10.1016/j.nmni.2015.05.005

Christie, L. J., Honarmand, S., Talkington, D. F., Gavali, S. S., Preas, C., Pan, C. Y., et al. (2007). Pediatric encephalitis: what is the role of Mycoplasma pneumoniae? Pediatrics 120, 305-313. doi: 10.1542/peds.2007-0240

Clyde, W. A. Jr. (1979). "Mycoplasma pneumoniae infections of man," in The Mycoplasmas II. Human and Animal Mycoplasmas, eds J. G. Tully and R. F. Whitcomb (New York, NY: Academic Press), 275-302.

Dégrange, S., Cazanave, C., Charron, A., Renaudin, H., Bebear, C., and Bebear, C. M. (2009). Development of multiple-locus variable-number tandem-repeat analysis for molecular typing of Mycoplasma pneumoniae. J. Clin. Microbiol. 47, 914-923. doi: 10.1128/JCM.01935-08

Dumke, R., Lück, P. C., Noppen, C., Schaefer, C., von Baum, H., Marre, R., et al. (2006). Culture-independent molecular subtyping of Mycoplasma pneumoniae in clinical samples. J. Clin. Microbiol. 44, 2567-2570. doi: 10.1128/JCM.0049506

Dumke, R., Schnee, C., Pletz, M. W., Rupp, J., Jacobs, E., Sachse, K., et al. (2015). Mycoplasma pneumoniae and Chlamydia spp. infection in communityacquired pneumonia, Germany, 2011-2012. Emerging Infect. Dis. 21, 426-434. doi: $10.3201 /$ eid2103.140927

Dumke, R., Strubel, A., Cyncynatus, C., Nuyttens, H., Herrmann, R., Lück, C., et al. (2012). Optimized serodiagnosis of Mycoplasma pneumoniae infections. Diagn. Microbiol. Infect. Dis. 73, 200-203. doi: 10.1016/j.diagmicrobio.2012.02.014

Ferguson, G. D., Gadsby, N. J., Henderson, S. S., Hardie, A., Kalima, P., Morris, A. C., et al. (2013). Clinical outcomes and macrolide resistance in Mycoplasma pneumoniae infection in Scotland, UK. J. Med. Microbiol. 62, 1876-1882. doi: 10.1099/jmm.0.066191-0

Foy, H. M. (1993). Infections caused by Mycoplasma pneumoniae and possible carrier state in different populations of patients. Clin. Infect. Dis. 17, S37-S46. doi: 10.1093/clinids/17.Supplement_1.S37

Gu, L., Chen, X., Li, H., Qu, J., Miao, M., Zhou, F., et al. (2014). A case of lethal hemolytic anemia associated with severe pneumonia caused by Mycoplasma pneumoniae. Chin. Med. J. 127, 3839.

Harris, M., Clark, J., Coote, N., Fletcher, P., Harnden, A., McKean, M., et al. (2011). British Thoracic Society guidelines for the management of community acquired pneumonia in children: update 2011. Thorax 66 (Suppl 2.), 1-23. doi: 10.1136/thoraxjnl-2011-200598

Ito, I., Ishida, T., Osawa, M., Arita, M., Hashimoto, T., Hongo, T., et al. (2001). Culturally verified Mycoplasma pneumoniae pneumonia in Japan: a long-term observation from 1979-99. Epidemiol. Infect. 127, 365-367. doi: $10.1017 / \mathrm{s} 0950268801005982$

Jacobs, E. (2012). Mycoplasma pneumoniae: now in the focus of clinicians and epidemiologists. Euro Surveill. 17:20084.

Kasahara, I., Otsubo, Y., Yanase, T., Oshima, H., Ichimaru, H., and Nakamura, M. (1985). Isolation and characterisation of Mycoplasma pneumoniae from cerbrospinal fluid of a patient with pneumonia and meningiencephalitis. J. Infect. Dis. 152, 823-825. doi: 10.1093/infdis/152.4.823

Kim, E. K., Youn, Y. S., and Rhim, J. W. (2015). Epidemiological comparison of three Mycoplasma pneumoniae pneumonia epidemics in a single hospital over 10 years. Korean J. Paediatr. 58, 172-177. doi: 10.3345/kjp.2015.58.5.172

Koletsky, R. J., and Weinstein, A. J. (1980). Fulminant Mycoplasma pneumoniae infection. Report of a fatal case, and a review of the literature. Am. Rev. Respir. Dis. 122, 491-496.
Korppi, M., Heiskanen-Kosma, T., and Kleemola, M. (2004). Incidence of community-acquired pneumonia in children caused by Mycoplasma pneumoniae: serological results of a prospective, population-based study in primary health care. Respirology 9, 109-114. doi: 10.1111/j.14401843.2003.00522.x

Lenglet, A., Herrador, Z., Magicrakos, A. P., Leitmeyer, K., and Coulombier, D. (2012). Surveillance status and recent data for Mycoplasma pneumoniae infections in the Eurpean Union and European economic area, January 2012. Euro Surveill. 17:20075.

Lim, W. S., Baudouin, S. V., George, R. C., Hill, A. T., Jamieson, C., Le Jeune, I., et al. (2009). Pneumonia Guidelines Committee of the, BTS guidelines for the management of community acquired pneumonia in adults: update 2009. Thorax 64(Suppl 3.), 1-55. doi: 10.1136/thx.2009.121434

Lind, K., Benzon, M. W., Jensen, J. S., and Clyde, W. A. Jr. (1997) A seroepidemiological study of Mycoplasma pneumoniae infections in Denmark over the 50-year period 1946-1995. Eur. J. Epidemiol. 13, 581-586.

Linde, A., Ternhag, A., and Torner, A. (2012). Antibiotic prescriptions and laboratory-confirmed cases of Mycoplasma pneumoniae during the epidemic in Sweden in 2011. Euro Surveill. 17:20082.

Meyer Sauteur, P. M., Bleisch, B., Voit, A., Maurer, F. P., Relly, C., Berger, C., et al. (2014a). Survey of macrolide-resistant Mycoplasma pneumoniae in children with community-acquired pneumonia in Switzerland. Swiss Med. Wkly. 144, w14041. doi: 10.4414/smw.2014.14041

Meyer Sauteur, P. M., Jacobs, B. C., Spuesens, E. B. M., Jacobs, E., Nadal, D., van Rossum, A. M., et al. (2014b). Antibody responses to Mycoplasma pneumoniae: role in pathogenesis and diagnosis of encephalitis? PLoS Pathog. 10:e1003983. doi: 10.1371/journal.ppat.1003983

Meyer Sauteur, P. M., van Rossum, A. M., and Vink, C. (2014c). Mycoplasma pneumoniae in children: carriage, pathogenesis, and antibiotic resistance. Curr. Opin. Infect. Dis. 27, 220-227. doi: 10.1097/QCO.0000000000000063

Narita, M. (2009). Pathogenesis of neurologic manifestations of Mycoplasma pneumoniae infection. Paediatr. Neurol. 41, 156-166. doi: 10.1016/j.pediatrneurol.2009.04.012

Narita, M. (2010). Pathogenisis of extrapulmonary manifestations of Mycoplasma pneumoniae infection with special reference to pneumonia. J. Infect. Chemother. 16, 162-169. doi: 10.1007/s10156-010-0044-X

Narita, M., Matsuzono, Y., Itakura, O., Togashi, T., and Kikuta, I. (1996). Survey of mycoplasma bacteremia detected in children by polymerase chain reaction. Clin. Infect. Dis. 23, 522-525.

Nguipdop-Djomo, P., Fine, E. M. P., Halsby, K. D., Chalker, V. J., and Vynnycky, E. (2013). Cyclic epidemics of Mycoplasma pneumoniae infections in England and Wales from 1975 to 2009: time-series analysis and mathematical modelling. Lancet 382(Suppl 3.), S78. doi: 10.1016/s0140-6736(13)62503-9

Nilsson, A. C., Bjorkman, P., Welinder-Olsson, C., Widell, A., and Persson, K. (2010). Clinical severity of Mycoplasma pneumoniae (MP) infection is associated with bacterial load in oropharyngeal secretions but not with MP genotype. BMC Infect. Dis. 10:39. doi: 10.1186/1471-2334-10-39

Nilsson, A. C., Jensen, J. S., Björkman, P., and Persson, K. (2014). Development of macrolide resistance in Mycoplasma pneumoniae-infected Swedish patients treated with macrolides. Scand. J. Infect. Dis. 46, 315-319. doi: 10.3109/00365548.2013.866268

Nir-Paz, R., Abutbul, A., Moses, A. E., Block, C., and Hidalgo-Grass, C. (2012). Ongoing epidemic of Mycoplasma pneumoniae infection in Jerusalem, Israel, 2010 to 2012. Euro Surveill. 17:20095.

Olson, L. D., Watkins, L. K., Demirjian, A., Lin, X., Robinson, C. C., Pretty, K., et al. (2015). Outbreak of Mycoplasma pneumoniae-associated Stevens-Johnson Syndrome. Pediatrics 136, 386-394. doi: 10.1542/peds.2015-0278

Omori, R., Nakata, Y., Tessmer, H. L., Suzuki, S., and Shibayama, K. (2015). The determinant of periodicity in Mycoplasma pneumoniae incidence: an insight from amthematical modelling. Sci. Rep. 5, 14473. doi: 10.1038/srep14473

Pereyre, S., Charron, A., Hidalgo-Grass, C., Touati, A., Moses, A. E., Nir-Paz, R., et al. (2012). The spread of Mycoplasma pneumoniae is polyclonal in both an endemic setting in France and in an epidemic setting in Israel. PLoS ONE 7:e38585. doi: 10.1371/journal.pone.0038585

Peuchant, O., Ménard, A., Renaudin, H., Morozumi, M., Ubukata, K., Bebear, C. M., et al. (2009). Increased macrolide resistance of Mycoplasma pneumoniae in France directly detected in clinical specimens by real-time PCR and 
melting curve analysis. J. Antimicrob. Chemother. 64, 52-58. doi: 10.1093/jac/ dkp160

Polkowska, A., Harjunpää, A., Toikkanen, S., Lappalainen, M., Vuento, R., Vuorinen, T, et al. (2012). Increased incidence of Mycoplasma pneumoniae pneumonia infection in Finland, 2010-2011. Euro Surveill. 17:20072.

Rasmussen, J. N., Voldstedlund, M., Anderson, R. L., Ellermann-Eriksen, S., Jensen, T. G., Johansen, H. K., et al. (2010). Increased incidence of Mycoplasma pneumoniae infections detected by laboratory-based surveillance in Denmark 2010. Euro Surveill. 15:19708.

Saïd, M. H., Layani, M. P., Faraj, G., Glastre, C., and Cochat, P. (1999). Mycoplasma pneumoniae-associated nephritis in children. Pediatr. Nephrol. 13, 39-44.

Sasaki, T., Kenri, T., Okazaki, N., Iseki, M., Yamashita, R., Shintani, M., et al. (1996). Epidemiological study of Mycoplasma pneumoniae infections in japan based on PCR-restriction fragment length polymorphism of the P1 cytadhesin gene. J. Clin. Microbiol. 34, 447-449.

Waites, K. B., Balish, M. F., and Atkinson, T. P. (2008). New insights into the pathogenesis and detection of Mycoplasma pneumoniae infections. Fut. Microbiol. 3, 635-648. doi: 10.2217/17460913.3.6.635
Waites, K. B., and Talkington, D. F. (2004). Mycoplasma pneumoniae and its role as a human pathogen. Clin. Microbiol. Rev. 17, 697-728. doi: 10.1128/CMR.17.4.697-728.2004

Zhao, F., Liu, G., Wu, J., Cao, B., Tao, X., He, L., et al. (2013). Surveillance of macrolide-resistant Mycoplasma pneumoniae in Beijing, China, from 2008 to 2012. Antimicrob. Agents Chemother. 57, 1521-1523. doi: 10.1128/AAC. 02060-12

Conflict of Interest Statement: The authors declare that the research was conducted in the absence of any commercial or financial relationships that could be construed as a potential conflict of interest.

Copyright (c) 2016 Brown, Nguipdop-Djomo, Zhao, Stanford, Spiller and Chalker. This is an open-access article distributed under the terms of the Creative Commons Attribution License (CC BY). The use, distribution or reproduction in other forums is permitted, provided the original author(s) or licensor are credited and that the original publication in this journal is cited, in accordance with accepted academic practice. No use, distribution or reproduction is permitted which does not comply with these terms. 